\title{
Preferred Learning Styles of Medical and Physiotherapy Students
}

\author{
Rahila Nizami, ${ }^{1}$ Muhammad Zahid Latif ${ }^{2}$, Gohar Wajid ${ }^{3}$
}

\begin{abstract}
Background: Learning styles are the ways students learn, intake and process new information. The contribution of learning styles for educational quality is evident and have important implications to develop effective curricula. Teachers can effectively plan instructional activities if they know the learning styles of students. This study was conducted to find out the preferred learning styles of medical and physiotherapy students.
\end{abstract}

Methods: This cross sectional descriptive study was conducted at Azra Naheed Medical College Lahore from January to March 2014. Honey and Muffard Learning Style Questionnaire (LSQ) was used to assess the preferred learning styles. The medical students of 3rd year and 6th semester physiotherapy class were invited for the study. The collected data was organized and analyzed by the use of statistical tools.

Results: 120 students participated in this study, out of which $60(50 \%)$ were students of MBBS class whereas $60(50 \%)$ were of physiotherapy class. $48(40 \%)$

\footnotetext{
${ }^{1} \mathrm{PhD}$ (Research Scholar), University of Management and Technology, Lahore.

${ }^{2} \mathrm{PhD}$ (Scholar), Director, Department of Medical Education, Associate Professor Community Medicine, Azra Naheed Medical College, Lahore.

${ }^{3}$ Technical Officer, Health Workforce Development World Health Organization
}

Date of Submission: 18-01-2017

Date of Acceptance for publication: 07-02-2017

Conflict of Interest: None

Funding Source: None

\section{Contribution}

All Authors have contributed in Study Design, Data Collection, Data Analysis, Data Interpretation, Manuscript Writing and Approval. were male students and $72(60 \%)$ were female students. Both the groups have reflector as dominating learning style with a minor difference of $(40 \%)$ and $(42.5 \%)$ for medical and physiotherapy respectively.

Conclusion: Students have different learning styles and require versatile instructional and assessment strategies. Preferred learning style of medical and physiotherapy students found in this study is reflector, however all the learning styles are present in both groups.

Key Words: Learning Styles. Learning Style Questionnaire, Reflector, Pragmatist, Theorist, Activist.

\section{Introduction}

Learning styles are the ways students learn, intake and process new information. ${ }^{1}$ Generally students have diverse types of learning styles and it is not possible to fix a better learning style. ${ }^{2}$ This diversity is related with ethnicity, culture, age, experience, environment and knowledge level of the learners. ${ }^{1}$ Research Studies draw different conclusions about the learning styles. ${ }^{3}$ It is important to understand the learning style of students as the learning styles of teachers and students are not the same. ${ }^{4}$ The contribution of learning styles for educational quality is evident and have important implications to develop effective curricula. ${ }^{5}$ Some researchers point out that learning styles, teaching styles and assessment are interlinked with each other.

Teachers can effectively plan instructional strategies and relevant activities if they know the learning styles of students. ${ }^{7}$ Similarly the knowledge of learning styles will help the teachers to solve the learning problems of the learners. ${ }^{8}$ Quality of learning process can easily be enhanced by matching the learning styles of students with the teaching methodology adopted by the faculty members. As a result the students will become more confident to manage their learning in the 
classes. ${ }^{1}$ The understanding of personal learning style is also necessary for self directed and life log learning. ${ }^{9}$

Keeping in mind the above mentioned scenario, this study was conducted to find out the preferred learning style of the MBBS and DPT students at Azra Naheed Medical College Lahore.

\section{Methods}

This was an observational, cross sectional study, conducted at Azra Naheed Medical College Lahore from January to May 2014. Using the non probability, convenient technique of sampling, the students of 3rd year MBBS class and 6th semester DPT class were invited to participate in this study. Honey and Muffard Learning Style Questionnaire (LSQ) was used to assess the preferred learning styles of both groups. ${ }^{10}$ Other than the questions of Honey and Muffard Learning style questionnaire (LSQ) the students were also asked to provide the data regarding age, gender, previous education, education of parents and family residential status. The two groups were approached separately in a lecture halls. After taking the consent, the authors explained the purpose and objective of the study. The format of the Learning Style Questionnaire (LSQ) was explained and different queries raised by the participants were clarified. The participants were given 30 minutes time to fill this questionnaire. The data collected from 120 participants was organized in two groups of 60 MBBS and 60 DPT students. Each questionnaire was analyzed to find out the preferred learning style of individual student. The data was categorized into four learning styles described by Honey and Muffard. ${ }^{11}$ A fifth category of two or more than two learning styles was also created. This data was entered in statistical package for social sciences (SPSS) version 16. Preferred learning styles of both study groups were presented in the form of frequencies and percentages.

\section{Results}

The Honey and Muffard Learning Style Questionnaire (LSQ) describe four different learning styles including activist, reflector, pragmatist and theorist. ${ }^{11} 120$ students participated in this study, out of which $60(50 \%)$ were of MBBS class whereas $60(50 \%)$ were of DPT class. $48(40 \%)$ were male students and $72(60 \%)$ were female students. Table 1 represent the residential status of students. $71(59.2 \%)$ students were of rural background, $14(11.7 \%)$ of urban families where as 35
(29.2\%) participants were having mix rural and urban residences. Parents education status of participants is represented in Table 2 . The students were asked to provide information about the education of any one or both of the parents. 47 (39.2\%) were bachelor degree holders, $41(34.2 \%)$ were master or above the master degree level. $23(19.2 \%)$ were intermediate where as 9 (7.5\%) parents were below the level of intermediate degree. Figure 3 and table 4 represents the preferred learning style of both MBBS and DPT students. Reflector is the single dominating learning style among the both groups where as the single second preferred style (16.7\%) among both groups is Pragmatist. However the second preferred learning style among both groups is the mix of different styles $(23.3 \%)$ as presented in Figure 3. The comparison of both groups is presented in Figure 4. It is evident from the results that both the groups have reflector as dominating learning style with a minor difference of $(40 \%)$ and $(42.5 \%)$ for MBBS and DPT classes respectively.

Table 1: Residence.

\begin{tabular}{|l|c|c|}
\hline & Frequency & Percentage \\
\hline Rural & 71 & 59.2 \\
\hline Urban & 14 & 11.7 \\
\hline Mix & 35 & 29.2 \\
\hline
\end{tabular}

Table 2: Parents Education.

\begin{tabular}{|l|c|c|}
\hline & Frequency & Percentage \\
\hline Below Intermediate & 41 & 34.2 \\
\hline Intermediate & 23 & 19.2 \\
\hline Bachelor & 47 & 39.2 \\
\hline Master or Above & 9 & 7.5 \\
\hline
\end{tabular}

Table 3: Preferred Learning Style.

\begin{tabular}{|l|c|c|}
\hline & Frequency & Percentage \\
\hline Reflector & 51 & 42.5 \\
\hline Mix & 28 & 23.3 \\
\hline Pragmatist & 20 & 16.7 \\
\hline Theorist & 12 & 10 \\
\hline Activist & 9 & 7.5 \\
\hline
\end{tabular}




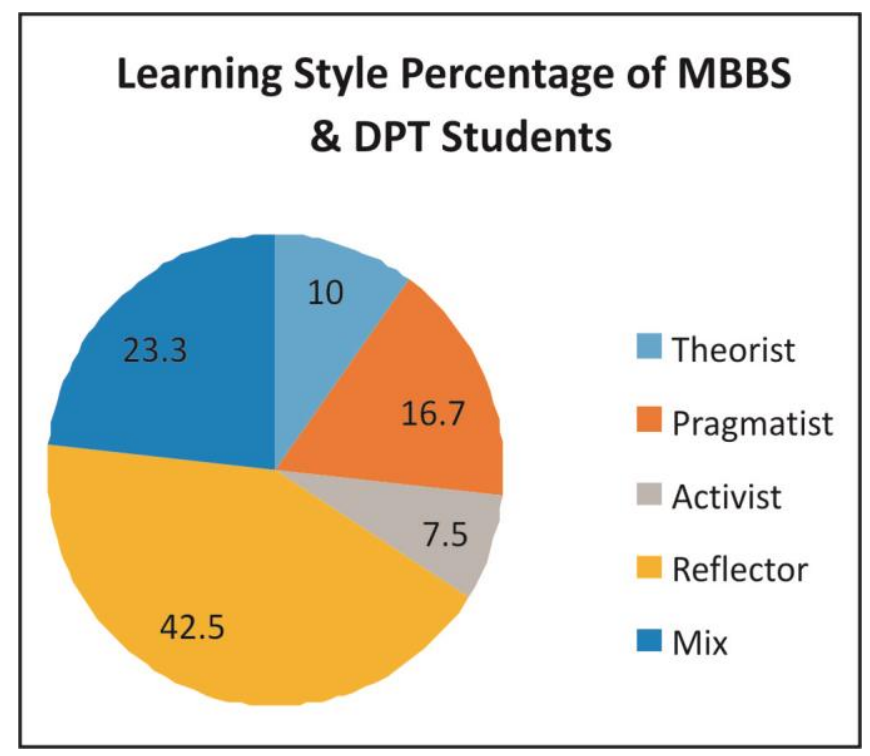

Fig. 1: Preferred Learning Style of MBBS \& DPT Students.

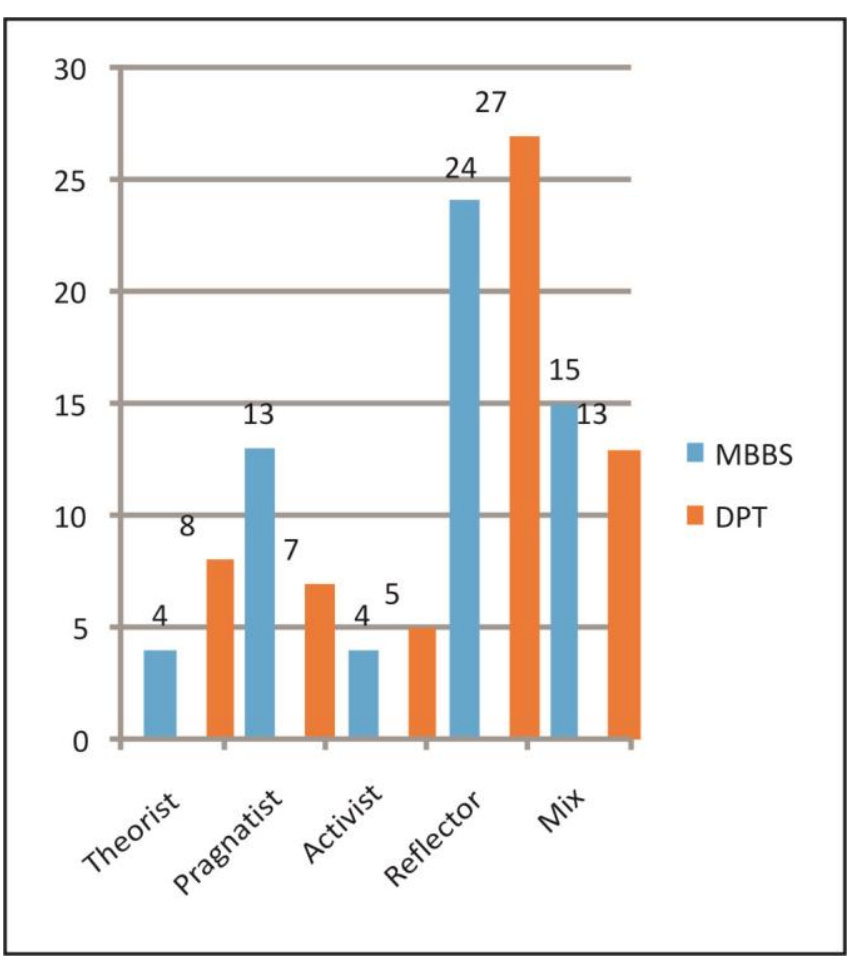

Fig. 2: Comparison of Preferred Learning Style of MBBS and DPT Students.

\section{Discussion}

Based on the experiential learning theory, four types of learners were identified. ${ }^{12}$ Activist is a person who, enjoys new experiences, and tends to make decisions intuitively, but dislikes structured procedures. Theorist focuses on ideas, logic and systematic planning, but are mistrustful of intuition and emotional involvement. Pragmatist likes practicality, down-to-earth approaches, group work, debate and risk-taking but tends to avoid reflection and deep levels of understanding. Reflector observes and describes processes, try to predict outcomes and focus on reflecting and trying to understand meaning. Honey and Mumford (1995) claimed that an individual tends to rely naturally on one of these approaches when they are engaged in learning or other task activities. ${ }^{12}$ The result of this research shows that reflector is the preferred learning styles in both the study groups. However all the learning styles are present (in variable proportion) in both the study groups. The presence of all the four learning styles in a class shows that the use of single teaching methodology is not suitable for the entire class. The preferred learning style should be kept in mind while designing the teaching and learning activities. Reflector as the preferred learning style in both the groups in this study differs from the result of another study at army medical college Rawalpindi which shows that undergraduates are predominately activist and postgraduate are reflectors. ${ }^{13}$ The results of another study represent that postgraduate residents of pediatrics are predominately reflectors. ${ }^{3}$ The data to compare these results is deficient among the medical students but the non medical students and professionals are mostly reflectors and pragmatists. ${ }^{14}$ This study shows that the Honey and Mufford Learning style Questionnaire (LSQ) can be used effectively to map the learning style of a class and to design instructional strategy accordingly. The study provides a learning style guidance for MBBS, DPT students and teachers.

\section{Conclusion}

Medical students have different learning styles and require versatile instructional and assessment strategies. Preferred learning style of medical and physiotherapy students found in this study is reflector, however all the learning styles are present in both groups. There is a growing need to study the preferred learning styles of medical students in Pakistan so that the faculty members can design matching learning activities. It will definitely help to improve the learning process and its outcome.

\section{References}

1. Prabha V, Geetha K, Doddamani B, Prakash M, Prakash SM. Learning styles among the first year medical students. Int J Pharm. 2013; 4 (2): 135-9. 
2. Coffield F, Moseley D, Hall E, Ecclestone K. Learning styles and pedagogy in post-16 learning: A systematic and critical review. 2004.

3. Juárez-Muñoz I, Gómez-Negrete A, Varela-Ruiz M, Mejía-Aranguré J, Mercado-Arellano J, Sciandra-Rico $\mathrm{M}$, et al. [Learning styles in medical residents and their professors of a pediatric hospital.]. Revista medica del Instituto Mexicano del Seguro Social. 2012; 51 (6): 614-9.

4. Budakoglu I, Erdemli E, Babadogan C. Learning styles of term 1 medical students in Turkish and English departments of medical faculty. Procedia-Social and Behavioral Sciences. 2012; 46: 3271-4.

5. Samarakoon L, Fernando T, Rodrigo C, Rajapakse S. Learning styles and approaches to learning among medical undergraduates and postgraduates. BMC medical education. 2013; 13 (1): 42.

6. Nuzhat A, Salem RO, Quadri MS, Al-Hamdan N. Learning style preferences of medical students: a singleinstitute experience from Saudi Arabia. International Journal of Medical Education. 2011; 2: 70-3.

7. Al BuAli WH, Balaha MH, Al Muhaidab NS. Assessment of Learning Style in a Sample of Saudi Medical Students. Acta Informatica Medica. 2013; 21 (2): 83.

8. Chinmay Shah N, JOSHI, H. B. Mehta, P. A. Gokhle.
Learning Styles Adopted By Medical Students. International Research Journal of Pharmacy. 2011; 2 (12): 227-9.

9. Kalaca S, Gulpinar M. A Turkish study of medical student learning styles. Education for Health. 2011; 24 (3): 459.

10. Honey P, Mumford A. The learning styles helper's guide: Peter Honey Maidenhead, Berkshire; 2000.

11. Honey P, Mumford A. Using your learning styles: Peter Honey Maidenhead, UK; 1986.

12. Mohamad SJANS. The Learning Styles of Early Adult Studens from Different Cultural Background in Malaysia 2009 03-07-2014 [cited 2014 July,03]. Available from:http://www.ou.nl/Docs/Campagnes/ICDE2009/Pa pers/Final_paper_550abdulnasir.pdf.

13. Shukr I, Zainab R, Rana MH. Learning styles of postgraduate and undergraduate medical students. Journal of College of Physicians and Surgeons Pakistan. 2013; 23: 25-30.

14. L.M.Martin AHa. Learning and thinking styles: A Tool for engaging engineering students with their studies. Available from:

http://www.hull.ac.uk/engprogress/Prog1Papers/Covent ryHalstead.pdf. 